\title{
Development of the solitary larval endoparasitoid Glyptapanteles porthetriae (Hymenoptera: Braconidae) in its host Lymantria dispar (Lepidoptera: Lymantriidae)
}

\author{
Christa NUSSBAUMER and AXEL SCHOPF \\ Institute of Forest Entomology, Forest Pathology and Forest Protection, University of Agricultural Sciences Vienna, \\ Hasenauerstrasse 38, A-1190 Vienna, Austria; e-mail: nussbaum@ento.boku.ac.at
}

Key words. Glyptapanteles porthetriae, Lymantria dispar, larval endoparasitoid, development

\begin{abstract}
The development of the solitary endoparasitic braconid Glyptapanteles porthetriae in gypsy moth larvae of different ages was studied. Host larvae were parasitized during the premolt to the 2 nd instar (A-larvae), to the 3rd instar (B-larvae) or to the 4th instar (C-larvae), respectively. The percentage of successfully parasitized larvae decreased markedly with the age of the host at the time of parasitization. When parasitization occurred at the premolt to the second or third instar, parasitoid larvae successfully emerged at rates of $68 \%$ and $57 \%$, respectively, in contrast to the $17 \%$ from larvae parasitized in the premolt to the fourth instar. In all three groups of parasitized larvae the final host instar was significantly longer than the corresponding instar of unparasitized control larvae of the same age. However, the growth and growth rate of parasitized larvae were reduced compared to control larvae. Due to the extremely low rate of successful development of $G$. porthetriae in C-larvae, parameters of parasitoid development were only recorded in $\mathrm{A}$ and B-host larvae. In both the parasitoid growth was slow during the first instar but rapidly increased during the second instar. Total developmental time of the parasitoid was significantly longer in B-host larvae, and the resultant cocoons were heavier than those that developed in A-host larvae, but proportionally fewer of the offspring were females. Within both groups the female wasps took significantly longer to develop than the males.
\end{abstract}

\section{INTRODUCTION}

Lymantria dispar is a serious pest of deciduous trees throughout the Northern temperate regions of the world. Accidentally introduced from Europe into the Eastern USA in 1869, the gypsy moth spread westwards generating damaging outbreaks due to the lack of natural enemies (Doane \& McManus, 1981). Between 1910 and 1992 many species of parasitoids from Europe and Asia were released in the USA, including Glyptapanteles porthetriae Muesebeck. This solitary braconid is one of the major larval parasitoid species of the gypsy moth and is considered an important natural enemy in Europe (Bathon, 1996; Burgess \& Crossman, 1929; Fuester et al., 1983; Raffa, 1977; Hoch \& Schopf, 1995; McManus \& McIntyre, 1981; Vasic, 1971). However, this species did not become established in the USA.

The life cycle of $G$. porthetriae is known from field observations. Female wasps parasitize early instar larvae of the gypsy moth, injecting a single egg into the host's haemocoel. A few days later, the first instar larva, which has distinct mandibles, hatches from the egg. About a week after hatching, the parasitoid larva molts into the second instar, which is recognized by reduced mandibles and a vesicle at the end of its abdomen. The vesicle is thin-walled and is thought to be permeable to various molecules. Shortly after the molt to the 2nd instar, the larva enters a phase of rapid growth, reaching a length which is often one third of the host's length. About a week after the first molt and before the end of the second instar, the vesicle is retracted and the fully grown parasitoid molts again, before emerging through the host's cuti- cle. The parasitoid larva spins a cocoon while the "empty" host larva remains alive for about 10 days, although feeding and locomotion are impaired. The pupal stage lasts about one week after which an adult wasp emerges, mates and the female wasps start parasitizing young host larvae a few hours later.

The goal of the present study was to investigate the basic parameters of the larval development of this parasitoid under laboratory conditions. A better understanding of host-parasitoid relationships is important for the successful implementation of the biological control of the gypsy moth and other pests.

\section{MATERIAL AND METHODS}

\section{Insects}

Gypsy moth eggs were obtained from a laboratory culture (gypsy moth rearing facility, USDA, OTIS Cape Cod, MA), and this strain of larvae was used rather than an indigenous population because of its highly synchronous growth and development. The larvae were reared in Petri dishes on an artificial diet (high wheat germ diet, Bell et al., 1981) under long day conditions $(16 \mathrm{~L}: 8 \mathrm{D})$ at $20^{\circ} \mathrm{C}$. G. porthetriae originated from a laboratory culture, which was started with cocoons collected in oak stands in eastern Austria in 1990. Adult wasps were reared under long day conditions in plastic boxes in the laboratory $\left(14-7^{\circ} \mathrm{C}\right)$, and were fed with honey and water.

\section{Host and parasitoid development}

The effects of host age on the development of the parasitoid were studied with gypsy moth larvae parasitized in the following 3 stages of development:

A-larvae: the premolt to the 2nd instar;

B-larvae: the premolt to the 3 rd instar; 
C-larvae: the premolt to the 4th instar.

A further group of unparasitized larvae (U-larvae) from the same egg clusters served as the control.

In order to prevent superparasitization host larvae were offered individually to female wasps. All larvae were checked every $24 \mathrm{~h}$, when molting or parasitoid emergence were recorded. Host larvae that were stung by a female wasp but did not give rise to a parasitoid were dissected in order to determine whether they were parasitized. These "potentially unparasitized" larvae did not show any sign of parasitization although they might have been stung and injected with venom, calyx fluid and an egg. If teratocytes (cells derived from the serosa of the parasitoid egg) but no parasitoid were found in the host's haemocoel, the larva was referred to as "pseudoparasitized".

\section{Developmental parameters of the host and the parasitoid}

Duration of the final host instar - the instar from which the parasitoid emerges - and growth $(\mathrm{G})$ of host larvae during the final host instar were monitored in the 3 categories of host larvae. Fresh weight gain was measured by weighing the host larvae at the beginning and at the end of the instar. Growth rates (GR) were estimated by dividing the biomass gained by the number of days spent in that instar. In order to convert fresh to dry mass, conversion factors (calculated from linear regression equations of fresh weight on dry weight for each category of larva) were used. Separate regression equations were calculated for each category of larvae at the beginning and at the end of the instar, based on 50 larvae each weighed before and after drying.

Due to the low parasitization of C-larvae, parasitoid development was only monitored in A and B-larvae. In order to monitor the growth of parasitoid larvae their approximate volume was calculated using the formula of a cylinder $\left(V=r^{2} \pi \cdot h\right)$. Length and width of each parasitoid was measured using a binocular microscope (Wild M8). The developmental time of a parasitoid was defined as the number of days between oviposition and the emergence of an adult wasp from a cocoon.

\section{Oviposition rate and fecundity of $G$. porthetriae}

As soon as they emerged from their cocoons six female wasps were each put separately in a box containing 3 males. Daily they were offered as many gypsy moth larvae (1st and 2 nd instar) as they could parasitize. These larvae were kept in separate Petri dishes and the emergence of parasitoids was recorded.

\section{Statistical analysis}

Most of the tests were carried out using SPSS for Windows 7.0. The specific method used to test for significance: U-test by Mann and Whitney, Kolmogorov-Smirnov-2-sample test, $\chi^{2}$ statistics or Spearman rank correlation coefficient, is mentioned in the result section.

\section{RESULTS}

\section{Parasitization efficiency}

As shown in Fig. 1 the percentage of parasitization decreased markedly with the age of the host larva at the time of parasitization. While $68 \%$ of A-larvae and $58 \%$ of B-larvae were parasitized the parasitization of C-larvae was much lower $(17 \%)$. There was no significant difference in the percentage of parasitization of $A-$ and B-larvae $\left(\chi^{2}=3.65\right)$ but a highly significant difference between that of $\mathrm{A}$ and C-larvae $\left(\chi^{2}=70.17\right.$; $\left.\mathrm{P}<0.001\right)$ and $\mathrm{B}-$ and $\mathrm{C}$-larvae $\left(\chi^{2}=70.22 ; \mathrm{P}<0.001\right)$, respectively. Although no pseudoparasitized A-larvae with teratocytes were found, low or similar percentage of B- $(6 \%)$ and C-larvae $(3 \%)$ were pseudoparasitized. Similar percent-

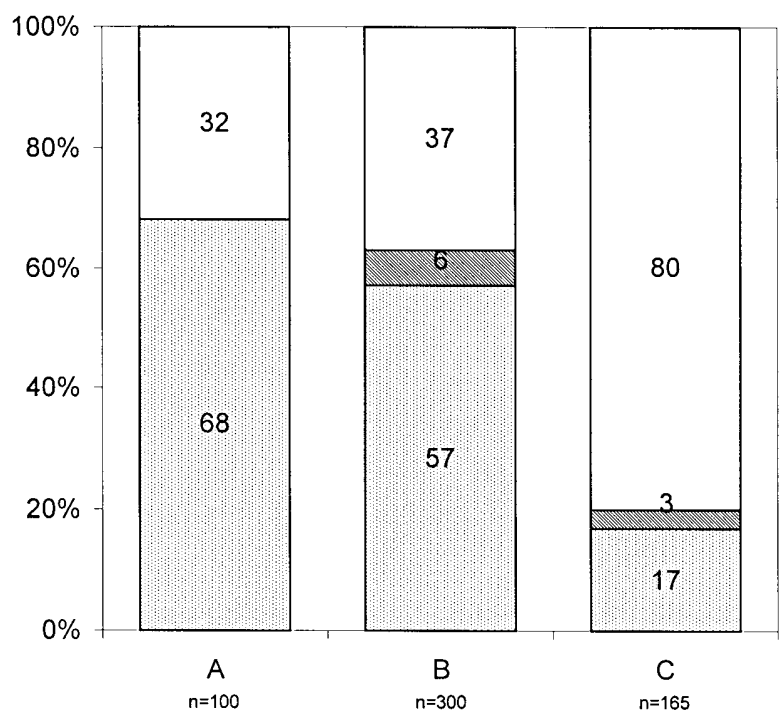

Fig. 1. Percentage of host larvae [oviposition at the end of the first (A), second (B) and third (C) instar] that were parasitized. Percentages of unparasitized larvae (white), pseudoparasitized larvae containing teratocytes (cross-hatched) and parasitized larvae containing a parasitoid larva (dotted).

ages, $32 \%$ and $37 \%$, of A- and B-larvae, respectively, contained neither a parasitoid nor teratocytes. Of the C-larvae most were of unknown status ( $80 \%)$, which was a significantly higher proportion than that recorded for Aor B-larvae and indicated that $G$. porthetriae had problems parasitizing or developing in 3rd instar larvae.

\section{Host development}

Final host instar

The majority of the parasitoids emerged from the next instar of the host after that parasitized. While $91 \%$ of the parasitoids in A-larvae emerged from the host its 3rd instar, only $9 \%$ emerged from a fourth instar larva. Of the parasitoids that were oviposited in B-larvae, 98\% completed their development in the 4th instar of the host, and very few emerged from third instar $(1 \%)$ or fifth instar (1\%) larvae. Most of the parasitoids that were oviposited in C-larvae were expected to emerge from 5 th instar host larvae. However, most emerged from 4th instar host larvae $(67 \%)$, and only $33 \%$ emerged from 5 th instar larvae. Thus, parasitoids from C-larvae emerged significantly more often from an earlier than from the 5th instar (U-test, $\mathrm{P}<0.001$ ).

Although parasitoid larvae were found in 6 th instar host larvae, none of them emerged. Even those in 5th instar hosts failed to break through the host's thick cuticle and died within the host.

\section{Duration of the final host instars}

While the development of the early instars of the host were unaffected by the parasitoid, the final host instar lasted significantly longer than that of unparasitized control larvae, independent of the time of parasitization (U-test; P $<0.001$; Table 1). Unparasitized 3rd instar larvae molted to the fourth instar after 5 days, however, A-larvae did not molt and the parasitoid emerged on the 
TABle 1. Duration in days of the instar of $L$. dispar from which the parasitoid emerged ( $\mathrm{m}$ - median; IQR - interquartile range; $\mathrm{n}$ - number) and fresh weight in $\mathrm{mg}(\mathrm{x}-$ mean; S.E. standard error). A L3 - A-host larvae at the end of the 3rd instar; U L3 - unparasitized control larvae at the end of the 3rd instar; B L4 - B-host larvae at the end of the 4th instar; C L4 C-host larvae at the end of the 4th instar; U L4 - unparasitized control larvae at the end of the 4th instar.

\begin{tabular}{lccccccc}
\hline & \multicolumn{3}{c}{ Duration (in days) } & & \multicolumn{3}{c}{ Fresh weight (mg) } \\
\cline { 2 - 4 } \cline { 6 - 8 } & $\mathrm{m}$ & IQR & $\mathrm{n}$ & & $\mathrm{x}$ & S.E. & $\mathrm{n}$ \\
\hline A L3 & 7 & 1 & 58 & & 40.56 & 1.09 & 57 \\
U L3 & 5 & 1 & 105 & & 92.81 & 2.35 & 73 \\
B L4 & 6 & 2 & 100 & & 88.4 & 1.87 & 98 \\
C L4 & 15.5 & 1.25 & 10 & & 120.38 & 5.9 & 8 \\
U L4 & 6 & 1 & 99 & & 299.93 & 15.17 & 39 \\
\hline
\end{tabular}

7th day. Control larvae spent 6 days in the 4th instar whereas B-larvae were still in the 4th instar on day 7 , when the parasitoids emerged. Those C-larvae that molted spent 17 days in the 4th instar before the parasitoids emerged.

Growth and growth rates during the final host instar

Although all the parasitized larvae spent longer in the final instars than the control larvae, the weight of parasitized larvae at the end of the final instar was significantly lower than that of the control larvae (U-test, $\mathrm{P}<0.001$; Table 1). Unparasitized larvae gained $60 \mathrm{mg}$ during the third instar while parasitized A-larvae gained only $16 \mathrm{mg}$ (Table 2). However, the small percentage of A-larvae from which parasitoids emerged during the 4th instar showed an equally high weight gain during the $3 \mathrm{rd}$ instar as the control larvae. In the 4th instar these larvae hardly gained any weight while the control larvae increased in weight by $219 \mathrm{mg}$. B-larvae also gained very little weight during the 4 th instar.

The growth rates based on fresh weight (FW) and dry weight (DW) are given in Table 2 . The regression coefficients of the relationships between the dry and fresh weights were 0.85 or higher (Table 3 ).

The growth rate of the 3rd instar A-larvae (13.4) that molted to the 4th instar, was similar to that of $3 \mathrm{rd}$ instar control larvae (15.0). Most A-larvae, however, which remained in the 3rd instar had a very low (3.3) growth rate. Fourth instar control larvae had a very high growth rate (43.7) compared to B-larvae of the same instar (3.0).

TABLE 2. Growth (mg increase in biomass) and growth rates of host larvae in the final instar based on fresh (FW) and dry weights (DW). AL3 emergence - 3rd instar A-larvae, parasitoid emerging from L3; AL3 molt - 3rd instar A-larvae, which molted to L4, parasitoid emerging from L4; UL3 molt - 3rd instar larvae unparasitized control; BL4 emergence -4 th instar B-larvae, parasitoid emerging from L4; UL4 molt - 4th instar larvae unparasitized control.

\begin{tabular}{lccccc}
\hline & \multicolumn{2}{c}{ growth $(\mathrm{mg})$} & & \multicolumn{2}{c}{ growth rate } \\
\cline { 2 - 3 } \cline { 5 - 6 } & FW & DW & & FW & DW \\
\hline AL3 emergence & 16.2 & 2.9 & & 3.3 & 0.4 \\
AL3 molt & 53.4 & 8.6 & & 13.4 & 2.2 \\
UL3 molt & 59.9 & 9.2 & & 15.0 & 2.3 \\
BL4 emergence & 18.1 & 3.2 & & 3.0 & 0.5 \\
UL4 molt & 218.6 & 29.2 & & 43.7 & 5.9 \\
\hline
\end{tabular}

TABLE 3. The relationship between dry weight (y) and fresh weight $(\mathrm{x})$ of $\mathrm{A}$ and B-host larvae at the beginning and end of the final instar and that of corresponding unparasitized control larvae.

\begin{tabular}{lcc}
\hline Larvae & Equation & Correlation coefficient $\left(\mathrm{r}^{2}\right)$ \\
\hline A L3D1 & $\mathrm{y}=0.1336 \mathrm{x}+0.0637$ & 0.8472 \\
A L3/L4 & $\mathrm{y}=0.1530 \mathrm{x}+0.0036$ & 0.9655 \\
B L4D1 & $\mathrm{y}=0.1219 \mathrm{x}+0.3012$ & 0.9473 \\
B L4L5 & $\mathrm{y}=0.1315 \mathrm{x}+0.4114$ & 0.9799 \\
U L3D1 & $\mathrm{y}=0.1168 \mathrm{x}+0.3184$ & 0.8539 \\
U L3L4 & $\mathrm{y}=0.1411 \mathrm{x}+0.2315$ & 0.9574 \\
U L4D1 & $\mathrm{y}=0.1243 \mathrm{x}+0.2975$ & 0.8974 \\
U L4/L5 & $\mathrm{y}=0.1298 \mathrm{x}+0.6413$ & 0.8747 \\
\hline
\end{tabular}

Growth rates were also calculated using dry weights. This gave similar results: the growth rates of the parasitized larvae were about one order of magnitude lower than that of the controls (Table 2).

\section{Parasitoid development}

Growth of the parasitoid larvae

In A-host larvae $75 \%$ of the parasitoid larvae molted to the second instar 9 days after parasitization. Similarly in B-host larvae, the majority of the parasitoid larvae (54\%) were in the second instar 9 days after parasitization. While first instar parasitoids grew very slowly (data not shown), second instar larvae showed a rapid increase in volume. B-host larvae were heavier than A-host larvae which does not correspond to the volumes of the parasitoids they contained. There was no significant difference in the volumes of parasitoids from A or B host larvae (U-test, Fig. 2). The increase in volume was marked in the second instar, especially 9 to 10 days after parasitization. A few days later, towards the end of the second instar, the growth of the parasitoid slowed down. Shortly before a parasitoid emerges its anal vesicle collapses and its size decreases markedly.

The parasitoid's volume was correlated with its age and instar. Moreover, both in host larvae A and B the parasi-

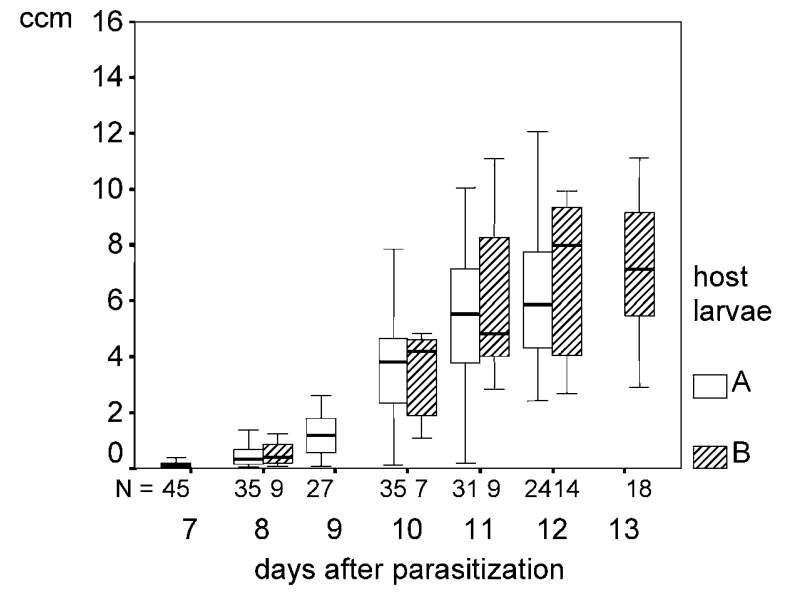

Fig. 2. The volumes (in $\mathrm{ccm}$ ) of second instar parasitoid larvae in A-host larvae (parasitized at the end of the first instar) and B-host larvae (parasitized at the end of the second instar). The horizontal line inside the box represents the median. The length of the box corresponds to the interquartile range (75th percentile -25 th percentile). Fifty percent of the observations had values that fell within the box. 


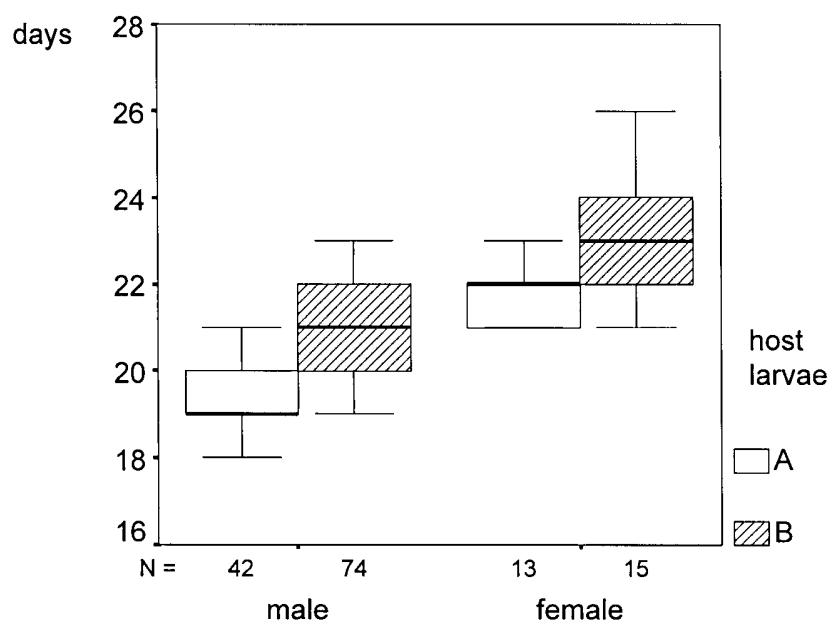

Fig. 3. Total developmental time (in days) of male and female parasitoid larvae in A-host larvae (parasitized at the end of the first instar) and B-host larvae (parasitized at the end of the second instar). The line inside the box represents the median. The length of the box corresponds to the interquartile range (25-75).

toid volume depended on the fresh weight of the host (Spearman, A: $\mathrm{r}^{2}=0.723, \mathrm{~B}: \mathrm{r}^{2}=0.633, \mathrm{P}<0.1$ ), but not its sex.

\section{Total developmental time (TDT)}

The number of days between parasitization and the emergence of the adult wasp strongly depended on which instar of the host was parasitized (Fig. 3). The wasp took significantly longer to develop in B- than in A-host larvae (Kolmogorov-Smirnov-Two-Sample test; $\mathrm{P}<0.001$ ). Both in A- and B-host larvae the TDT of females of $G$. porthetriae was significantly longer than that of males $(\mathrm{P}<0.001)$. This partly resulted from the duration of the pupal stage, which was longer for females than for males, which emerged from both $\mathrm{A}-(\mathrm{P}<0.001)$ and $\mathrm{B}$-host larvae ( $\mathrm{P}<0.001$; data not shown). Only $2.3 \%$ of the wasps in $\mathrm{A}$ - and $1.8 \%$ of those in B-host larvae did not emerge from their cocoons. Sex ratios from parasitoids that developed in A- and B-host larvae differed. It was $1: 3$ and $1: 5$ female to male ratios for parasitoids from A- $(n=153)$ and B-host larvae $(n=157)$, respectively.

Although there was no correlation between the weight of the empty carcass of a host larva and that of the cocoon spun by the parasitoid, the cocoons produced by parasitoids emerging from B-host larvae were significantly heavier than those from the smaller A-host larvae (U-test, median $=4.2 \mathrm{mg}$, IQR (inter quartile range) $=0.5$ for A-larvae; median $=5 \mathrm{mg}, \mathrm{IQR}=1$ for $\mathrm{B}$-larvae; $\mathrm{P}<$ $0.05)$.

\section{Oviposition rate}

Females offered daily as many host larvae as they could parasitize, lived between 21 and 32 days, whereas the males died after 14 to 38 days. All the females started ovipositing on the day they emerged or the next day, and all but one parasitized host larvae every day until they died. On average, each female parasitized 5 host larvae per day, with a maximum of 15 larvae per day $(n=154$ days). Parasitoids emerged from only $21 \%$ of the putatively parasitized larvae. The total number of larvae attacked during a parasitoid's lifetime was between 114 and 371 .

\section{DISCUSSION}

\section{Parasitization efficiency and host suitability}

The present study provides strong evidence that host age plays a major role in host suitability for $G$. porthetriae. Young host larvae were more frequently parasitized than older hosts. While there was no difference between A $(68 \%)$ and B (57\%) larvae, significantly fewer parasitoids developed in $\mathrm{C}$-larvae $(17 \% ; \mathrm{P}<0.001)$. All the other larvae were either pseudoparasitized or unparasitized, which amounted to more than $80 \%$ in the case of $\mathrm{C}$-larvae. There are many reasons why older hosts are not successfully parasitized by this species. Even though a large host is often a better food source for a parasitoid larva, it may be better defended, both physically and physiologically. Older larvae may be better able to defend themselves against female wasps or have thicker, less penetrable cuticles, which present a physical barrier. However, Glyptapanteles liparidis, a closely related species, attacks and develops in L3 larvae (Schopf, 1991; Steinberger, 1991) even though this wasp is smaller and more fragile than G. porthetriae. Host suitability may also be influenced by certain aspects of host age such as the physiological conditions in the host associated with molting. Another major factor influencing parasitoid survival is how well adapted they are to cope with the host's cellular encapsulation system, which is likely to be the main factor determining host suitability for most endoparasitoid species (Godfray, 1994). The effectiveness of a host's cellular immune system against parasitoid attack often depends on the size of the host (Salt, 1968). In the gypsy moth the immune response is certainly stronger in older larvae. Encapsulation occurs at a high rate in C-larvae and this and other aspects of the host's defense are described elsewhere (Nussbaumer, 1998).

\section{Host development}

For parasitoids developing in A-larvae the final host instar was mainly L3 and in B- and C-larvae it was mainly L4. A few parasitoids emerged from A-larvae when in L4 and very few from B- or C-larvae when in L5. Initially it seemed as if some parasitoid larvae needed an additional host instar (L4 in A-larvae or L5 in B-larvae) in order to reach a biomass that would enable them to complete their development successfully. However, the fresh weight at the beginning of L3 in A-larvae, from which the parasitoid larvae emerged during L3, did not differ significantly from the fresh weight of A-larvae, which molted to L4 before the parasitoid completed its development. Moreover, parasitoids from A-larvae that molted to L4 were smaller than parasitoids of the same age that emerged from L3. These facts indicate, that an additional host instar might be necessary for parasitoid larvae that grow more slowly than usual. The main impact 
on host growth, which usually occurs during L3 in A-larvae and L4 in B-larvae, occurs in the next instar. Parasitoid development is prolonged, possibly because it cannot control the host's development.

Conditions prevailing in C-larvae are different from those in A- and B-larvae. Hardly any parasitoids developed in C-larvae. The fourth host instar seems to be the last, from which $G$. porthetriae larvae are able to emerge. Therefore, C-larvae are unsuitable hosts for $G$. porthetriae.

The latter host instars, no matter whether L3, L4 or L5, were significantly prolonged if parasitized, compared to control larvae. Parasitism slows the host larval development and the parasitoid is thus able to finish its development in an earlier host instar than one would expect from the age of the host. This is a very common mechanism in host-parasitoid systems. For example, larvae of Manduca sexta parasitized by Cotesia congregata remain in a certain larval instar even though their weight exceeds that required in this species for metamorphosis (Alleyne \& Beckage, 1997).

Growth rates of parasitized hosts are only affected during the final host instar when they are parasitized by the solitary parasitoid, G. porthetriae, and the closely related gregarious species, $G$. liparidis (Schopf \& Steinberger, 1996). Reduced feeding rates have frequently been recorded for parasitized larvae and those infected with pathogens. This causes a decline in the rate of food consumption and in the growth rate, and on extended larval development as it takes them longer to reach the minimum critical size required to initiate larval ecdysis or metamorphosis (Beckage, 1997).

\section{Parasitoid development}

Adult biomass and development time are two of the chief determinants of fitness (Mackauer \& Sequeira, 1993). Thus, developmental strategies appear to be based on trade-offs that result in optimization of both adult biomass and development time.

In some koinobiont braconid parasitoids of aphids, development is fastest in smaller hosts (Kouamé \& Mackauer, 1991), while in other species the time required for development is relatively constant (Mackauer, 1986). $G$. porthetriae larvae from the small $\mathrm{A}-$ and large B-larvae do not differ in duration of their first instar but their second instar takes on average one day longer in B-larvae. This explains why pupae of $G$. porthetriae from B-larvae are heavier than from A-larvae although growth and growth rates of the parasitoid (data not shown) are similar in these larvae. Duration of the pupal instar is also one day longer for parasitoids emerging from $\mathrm{B}$ than from A-larvae. In general, the development time of $G$. porthetriae depends on age of the host at parasitization. Parasitoids that developed in A- and B-host larvae had similar development times. Too few parasitoids emerged from C-larvae for statistical evaluation. According to the field studies by Schopf et al. (1997) cocoons of $G$. porthetriae emerged in the field from second, third and fourth instar gypsy moth larvae.
Like the gregarious $G$. liparidis (Schopf, 1991), the solitary species, $G$. porthetriae, grows very slowly in its first instar and completes most of its growth in volume within a few days of entering the second instar. Thus, the parasitoid keeps its impact on the host's growth to a minimum for as long as possible, which enables the host to grow and accumulate resources for the parasitoid's development. It is likely parasitoids have to reach a certain threshold size before they can molt to the second instar, as reported for other insects (Jones et al., 1981; Nijhout, 1981). In G. porthetriae, most of the larvae molted 9 days after oviposition when their minimum volume was $0.49 \mathrm{~mm}^{3}$ in both $\mathrm{A}$ - and B-host larvae. This may be the critical body volume for this species.

Braconids, such as Cotesia congregata (Beckage \& Riddiford, 1982), Cotesia glomerata (Führer \& Keja, 1976) and Hyposoter exiguae (Smilowitz, 1974), remain in the first instar until the host molts into its final instar. In this case, molt of the parasitoids is linked to the host's final larval molt. The host's elevated ecdysteroid titer during this phase could serve as a trigger. If $G$. porthetriae also depends on the host molting, then parasitoids in C-larvae would not be able to complete their larval development and emerge from L4 since the host only molts once, one day after parasitization (L3/L4). Furthermore, during their field studies Schopf et al. (1997) collected cocoons of $G$. porthetriae that emerged from second instar gypsy moths, which also supports our assumption.

Unlike Cotesia species, the two Glyptapanteles species, which parasitize gypsy moth larvae, have a wider host range. Since the gypsy moth overwinters as an egg, Glyptapanteles needs another species of host for hibernation. Thus, the relation between host and parasitoid in this system is probably not as close as in other host-parasitoid systems.

While the size of adult idiobiont parasitoids is strongly correlated with the size of the host in which it develops, that of koinobiont parasitoids is often independent of host size (Godfray, 1994). There was no correlation between the fresh weight of gypsy moth A- and B-larvae one day after parasitization and the weight of the cocoon of $G$. porthetriae (data not shown). Similarly the weight of $L$. dispar, shortly before or after the parasitoid emerged, was not correlated with parasitoid volume or with the parasitoid's pupal weight. This solitary parasitoid does not use all of the host's resources during its development. As long as there is surplus food for the parasitoid in small hosts there is no advantage in parasitizing a larger host. Comparison of cocoon weights of parasitoids emerging from A- and B-larvae, however, showed that the larger B-larvae produced heavier parasitoid pupae. This means, that within A- and B-larvae the differences in host weight were not large enough to result in differences in parasitoid pupal weight, whereas the smaller A-larvae gave rise to smaller parasitoid pupae than the larger B-larvae.

The fecundity and hence fitness of female wasps is strongly correlated with adult size (King, 1987; Rosenheim \& Rosen, 1991). The size may influence fitness by 
affecting searching efficiency, longevity, or egg supply. Male fitness will be largely determined by the number of matings achieved. Male wasps may also benefit from being large, but small size probably impairs mating less than it impairs oviposition (Godfray, 1994). In accordance with these observations, female pupae of $G$. porthetriae are heavier than male pupae that emerged from both A- and B-host larvae.

Hymenoptera have a haplodiploid genetic system, which means that males develop from unfertilized eggs and females from fertilized eggs. The sex of the egg is thus under the control of the mother, which makes it easy for natural selection to adapt the sex ratios to local conditions. That is why the sex ratio of $G$. porthetriae in the laboratory probably differs from that observed in the field. In this study $33 \%$ of the parasitoids that emerged from A-larvae were females and $20 \%$ of those from B-larvae were females.

\section{Usefulness of $G$. porthetriae as an antagonist of the gypsy moth}

The importance of $G$. porthetriae for regulating gypsy moth populations, has been assessed in several field studies (Burgess \& Crossman, 1929; Vasic, 1971; McManus \& McIntyre, 1981; Bathon, 1996; Schopf et al. 1997). As indicated in the present study, this oligophagous species parasitizes the early instars of the gypsy moth and kills its host mainly during the $3 \mathrm{rd}$ instar and 4th instar. In the field the majority of the gypsy moth larvae killed by $G$. porthetriae died during the 4th instar. $G$. porthetriae reduces the damage done by gypsy moth more than parasitoids that kill the late larval stages as the feeding activity of $L$. dispar increases dramatically in the 4th instar (Leonard, 1970). Our results indicate that by the fourth instar the parasitized larvae are either dead or growing very slowly, probably due to a decrease in feeding rates. Supposedly, the parasitoid does not passively affect the host simply by its presence but actively modulates the host's development. The extension of the final instar of the host by preventing it from molting is associated with a late stage in the development of the parasitoid larvae. However, this might be caused by hormonal disruption of the host. A drastic decrease in the juvenile hormone metabolizing enzyme, juvenile hormone esterase, during the late larval development of the parasitoid has been reported elsewhere (Nussbaumer, 1998) and supports the assumption that one of the main hormones regulating development, the juvenile hormone, might be affected. Our data show that this parasitoid develops very fast and spends only one week in the defenseless pupal instar, which makes it less prone to hyperparasitization than other parasitoids of the early instar of the gypsy moth, like Cotesia melanoscela (Eichhorn, 1996). Moreover, G. porthetriae overwinters as a late 1st instar larva inside an alternate host, while the overwintering cocoons of $C$. melanoscela are exposed to attack by hyperparasites from July to May. Compared to the more specialized braconid, C. melanoscela, which shows a similar developmental pattern, $G$. porthetriae may react faster to changes in host abundance.
The G. porthetriae-L. dispar system is an ideal one for investigating the endocrine regulation of development and host-parasite interactions. A greater insight into the mechanisms this parasitoid uses to regulate its host will help in the development of new strategies for pest control.

ACKNOWLEDGEMENTS. The authors would like to thank G. Bernon of the gypsy moth rearing facility (USDA, OTIS Cape Cod, MA) for providing gypsy moth egg masses and A. Stradner for excellent technical assistance and insect rearing.

\section{REFERENCES}

Alleyne M. \& BeCKage N.E. 1997: Parasitism-induced effects on host growth and metabolic efficiency in tobacco hornworm larvae parasitized by Cotesia congregata. J. Insect Physiol. 43: 407-424.

BATHON H. 1996: Zur Bedeutung der Parasitoide beim Zusammenbruch der Schwammspinner-Gradation in Südhessen. Mitt. Biol. Bundanst. Land-Forstw. 332: 74-90.

BeCKAGE N.E. 1997: New insights: How parasites and pathogens alter the endocrine physiology and development of insect hosts. In Beckage N.E. (ed.): Parasites and Pathogens: Effects on Host Hormones and Behavior. Chapman and Hall, New York, pp. 3-36.

BECKAGE N.E. \& RiDDIFORD L.M. 1982: Effects of parasitism by Apanteles congregatus on the endocrine physiology of the tobacco hornworm Manduca sexta. Gen. Comp. Endocrinol. 47: $308-322$.

Bell R.A., Owens C.D., Shapiro M. \& TardiF J.R. 1981: Development of mass-rearing technology. In Doane C.C. \& McManus M.L. (eds): The Gypsy Moth: Research Toward Integrated Pest Management. U.S.D.A. Tech. Bull. No. 1584, pp. 599-633.

Burgess A.F. \& Crossman S.S. 1929: Imported insect enemies of the gypsy moth and the brown-tail moth. U.S.D.A. Tech. Bull. No. 86,124 pp.

Doane C.C. \& McManus M.L. 1981: The Gypsy Moth: Research toward integrated pest management. U.S.D.A. Tech. Bull. No. 1584,757 pp.

EICHHORN O. 1996: Experimental studies upon the parasitoid complex of gypsy moth in lower host population in eastern Austria. J. Appl. Entomol. 120: 205-212.

Fuester R.W., Drea J.J., Gruber F., Hoyer H. \& Mercadier G. 1983: Larval parasites and other natural enemies of Lymantria dispar (Lep.: Lymantriidae) in Burgenland, Austria, and Würzburg, Germany. Envir. Entomol. 12: 724-737.

FüHrER E. \& KeJA T.D. 1976: Physiologische Wechselbeziehungen zwischen Pieris brassicae und dem Endoparasiten Apanteles glomeratus. Der Einfluss der Parasitierung auf Wachstum und Körpergewicht des Wirtes. Entomol. Exp. Appl. 19: 287-300.

Godfray H.C.J. 1994: Parasitoids: Behavioral and Evolutionary Ecology. Princeton University Press, Princeton, New Jersey, $473 \mathrm{pp}$.

Jones G., Wing K.D., Jones D. \& Hammock B.D. 1981: The source and action of head factors regulating juvenile hormone esterases in larvae of the cabbage looper, Trichoplusia ni. $J$. Insect. Physiol. 27: 85-91.

KING B.H. 1987: Offspring sex ratios in the parasitoid wasps. $Q$. Rev. Biol. 62: 367-396.

KoUAmé K.L. \& MACKAUER M. 1991: Influence of aphid size, age and behaviour on host choice by the parasitoid wasp Ephedrus californicus: A test of host-size models. Oecologia 88: 197-203. 
LEONARD D.E. 1970: Feeding rhythm in larvae of the gypsy moth. J. Econ. Entomol. 63: 1454-1457.

MACKAUER M. 1986: Growth and developmental interactions in some aphids and their hymenopteran parasites. J. Insect Physiol. 32: 275-280.

Mackauer M. \& Sequeira R. 1993: Patterns of development in insect parasites. In Beckage N.E., Thompson S.N. \& Federici B.A. (eds): Parasites and Pathogens of Insects. Academic Press, New York, pp. 1-24.

McManus M.L. \& McIntyre T. 1981: Introduction. In Doane C.C. \& McManus M.L. (eds): The Gypsy Moth: Research toward integrated pest management. U.S.D.A. Tech. Bull. No. 1584 , pp. $1-7$.

Ninhout H.F. 1981: Physiological control of molting insects. Am. Zool. 21: 631-640.

NussBaumer C. 1998: Biology of the Solitary Braconid, Glyptapanteles porthetriae and its Influence on the Juvenile Hormone Metabolism of its Host Lymantria dispar. $\mathrm{PhD}$ thesis, University of Vienna, $124 \mathrm{pp}$

RAFFA K. 1977: Potential alternate host of the gypsy moth parasite Apanteles porthetriae. Envir. Entomol. 6: 57-59.

RosenHeIM J.A. \& Rosen D. 1991: Foraging and oviposition decision in the parasitoid Aphytis lingnanensis: Distinguishing the influences of egg load and experience. J. Anim. Ecol. 60: 873-894.
SALt G. 1968: The resistence of insect parasitoids to the defence reactions of their hosts. Biol. Rev. 43: 200-232.

SCHOPF A. 1991: The effect of host age of Lymantria dispar larvae on the development of Glyptapanteles liparidis. Entomophaga 36: 593-604.

Schopf A. \& SteinBerger P. 1996: The influence of endoparasitic wasp Glyptapanteles liparidis on the growth, food consumption, and food utilization of its host larva, Lymantria dispar. Eur. J. Entomol. 93: 555-568.

Schopf A., Носн G., Novotny J. \& Zurrik M. 1997: Zur Populationsdynamik des Schwammspinners, Lymantria dispar (Lep.: Lymantriidae). Endbericht des Projektes 45.273/2 46a/93, BMWF Vienna, $91 \mathrm{pp}$.

Smicowitz Z. 1974: Relationships between the parasitoid Hyposoter exiguae and cabbage looper, Trichoplusia ni: Evidence for endocrine involvement in successful parasitism. Ann. Entomol. Soc. Am. 67: 317-320.

STEINBERGER P. 1991: Beeinflussung des Stoffwechsels von Lymantria dispar durch die Parasitierung mit Glyptapanteles liparidis. Thesis, University of Vienna, $58 \mathrm{pp}$.

VASIC K. 1971: A Biological Method of Control of Lymantria dispar and Diprion pini. Final tech. rep. 1967-1971. U.S. Dep. Agric. For. Serv., Hamden, Conn., 23 pp.

Received April 7, 1999; accepted February 23, 2000 